\title{
Principles of ethical prescribing for self and others: hydroxychloroquine in the COVID-19 pandemic
}

\section{Ian Coombes \\ Director, Department of Pharmacy \\ Associate professor, School of Pharmacy²}

\section{Alexandra Markwell \\ Senior staff specialist, \\ Emergency and Trauma \\ Centrel \\ Senior lecturer, Faculty of Medicine $^{2}$ \\ Chair $^{3}$}

\section{Paul Kubler}

Director, Department of Rheumatology'

Senior lecturer, Faculty of Medicine $^{2}$

\section{Andrew M Redmond}

Acting director, Department of Infectious Diseases'

Senior lecturer, Faculty of Medicine ${ }^{2}$

\section{Gordon McGurk}

Chairperson, Human

Research Ethics Committee

\section{Jason A Roberts}

Consultant clinical pharmacist, Departments of Pharmacy and Intensive Care Medicine ${ }^{\top}$ Professor, University of Queensland Centre for Clinical Research, Faculty of Medicine and School of Pharmacy²

\section{'Royal Brisbane and}

Women's Hospital, Brisbane

2 The University of

Queensland, Brisbane

${ }_{3}^{3}$ Queensland Clinical Senate, Queensland Health, Brisbane

\section{Keywords}

COVID-19, ethics, hydroxychloroquine

Aust Prescr 2020;43:76-7 https://doi.org/10.18773/ austprescr.2020.030

First published 22 April 2020
Prescribing medicines with putative benefit for COVID-19 disease appears very attractive to consumers, clinicians and some senior politicians. However, there are no medicines with any robust evidence of clinical benefit, including the antimalarial hydroxychloroquine, the antibiotic azithromycin and the antiretroviral combination of lopinavir with ritonavir. Indeed, now is the time to investigate which drugs may improve clinical outcomes in COVID-19 by conducting well-designed clinical trials, rather than making assumptions based on preliminary data and low-quality clinical studies. ${ }^{2}$ There are major trials underway in hospital wards and intensive care units, as well as in the community in the USA, Europe and Australia. Each trial will test different drugs or drug combinations, driven by locally available options. ${ }^{3}$

Hydroxychloroquine is registered in Australia for the treatment of patients with systemic lupus erythematosus, rheumatoid arthritis and malaria. It has proven benefit in these indications and is generally well tolerated by these patients. It is not yet registered for the treatment of COVID-19 in Australia and the drug toxicity profile in COVID-19 is currently unknown. It may prove to be dependent on both the patient population, the dose administered and the concomitant drug therapies. Without knowing the effective drug concentrations, non-optimised dosing may expose patients to serious adverse effects, such as seizures and cardiac toxicity. ${ }^{4}$

Some clinicians and consumers may believe that hydroxychloroquine should be available on compassionate grounds for patients with COVID-19 who are not eligible or do not give their consent for recruitment into a clinical trial. ${ }^{5}$ Hydroxychloroquine should only be prescribed after the patient or their carer has been made aware of the drug's potential toxicities and its lack of proven efficacy in COVID-19, and consent has been given.

There are also proposals from some clinicians to take hydroxychloroquine prophylactically following high-risk exposure such as intubating or extubating infected patients. Although pre-exposure and post-exposure prophylaxis trials have already commenced, or will do so imminently, the use of hydroxychloroquine should be conserved for proven therapeutic indications or as part of a randomised controlled trial. ${ }^{6}$

Due to inappropriate prescribing and dispensing, hydroxychloroquine is now in short supply in Australia and globally. This has caused serious challenges for patients receiving ongoing treatment for chronic diseases such as lupus for which there often is not an effective alternative, ${ }^{7}$ and even temporary withdrawal can lead to serious harm. ${ }^{8}$ While patients with rheumatoid arthritis could be managed with alternative diseasemodifying drugs, this is inconvenient as they need to have additional specialist consultations. It is encouraging that pharmacy and medical professional organisations are also conveying similar messages regarding the limited evidence of drug efficacy and safety in COVID-19, as well as the importance of ongoing access to essential treatments for chronic diseases. ${ }^{9,10}$

There may be a temptation to self-prescribe hydroxychloroquine or prescribe it for family and friends. Each state and territory has specific legislation that regulates this type of prescribing. The Good Medical Practice guide from the Medical Board of Australia cautions against prescribing for self, family, friends or coworkers. The Guide recommends 'seeking independent, objective advice when you need medical care, and being aware of the risks of self-diagnosis and self-treatment'." In other words, all health professionals should have their own doctor. The guide also advises doctors against providing medical care to anyone with whom they have a close personal relationship because of the lack of objectivity, possible discontinuity of care and the risks to the doctor and patient.

Some may argue that in a pandemic, prescribing outside of the guidelines is justified. However, from a medico-ethical and possibly legal perspective, the answer should be 'no' when considering a request to prescribe for a family member or close friend..$^{12}$ If you 
are asked for such a prescription, it is important to ask yourself:

- Have I made an objective and independent decision to prescribe the most suitable medicine for the condition in this situation?

- Am I able to provide appropriate care for my family or friend?

- Am I following my usual practice and scope in prescribing in this situation?

- Would my peers agree that this was consistent with good practice?

- Would our relationship survive, and could I be considered as having not executed my duty of care or even of being negligent if an adverse drug event occurred?

Prescribing medicines for COVID-19 lacks evidence, risks toxicity and may prevent others accessing essential treatments for chronic diseases. Using hydroxychloroquine or other unproven medicines as a possible standard of care for the treatment or prevention of COVID-19 raises ethical issues of resource allocation as well as beneficence. Drugs must be reserved for approved indications for which they are a first-line treatment. Conversely, while many are hopeful that hydroxychloroquine may prove to be the panacea that will help us lessen the effect of COVID-19 in the population, its use outside of a clinical trial should be avoided until more evidence is available. ${ }^{13}<$

lan Coombes is the Director of the Royal Brisbane and Women's Hospital pharmacy department, which has an interim licence to support pharmacy activities associated with COVID-19 clinical trials, including the Australasian COVID-19 Trial (ASCOT) involving hydroxychloroquine.

Andrew Redmond is an associate investigator and Jason Roberts is an investigator on the ASCOT study. Funding for this study has come from donors and the authors do not receive any financial advantage for their participation.

Paul Kubler is principal site investigator for Abbvie for two phase III trials on drugs for psoriatic arthritis and systemic lupus erythematosus. He does not receive any financial benefit for participation. Funding goes to a public hospital research trust fund.

\section{REFERENCES}

1. Thomas K, Grady D. Trump's embrace of unproven drugs to treat coronavirus defies science. New York Times 2020 Mar 20. https://www.nytimes.com/2020/03/20/health/ coronavirus-chloroquine-trump.html [cited 2020 Mar 20]

2. Kim AHJ, Sparks JA, Liew JW, Putman MS, Berenbaum F, Duarte-García A, et al; COVID-19 Global Rheumatology Alliance. A rush to judgment? Rapid reporting and dissemination of results and its consequences regarding the use of hydroxychloroquine for COVID-19. Ann Intern Med 2020 Mar 30 [Epub ahead of print]. https://doi.org/10.7326/M20-1223

3. Adaptive COVID-19 Treatment Trial. ClinicalTrials.gov identifier: NCT04280705. First posted 2020 Feb 21. https:/clinicaltrials.gov/ct2/show/NCT04280705?term=rem desivir\&cond=covid-19\&draw=2\&rank=5 [cited 2020 Mar 20]

4. Ruiz-Irastorza G, Ramos-Casala M, Brito-Zeron P Khamashta MA. Clinical efficacy and side effects of antimalarials in systemic lupus erythematosus: a systematic review. Ann Rheum Dis 2010;69:20-8. https://doi.org/10.1136/ ard.2008.101766

5. The Council of Australian Therapeutic Advisory Groups. Rethinking medicines decision-making in Australian hospitals: guiding principles for the quality use of off-label medicines. Sydney: CATAG; 2013. http://www.catag.org.au/rethinkingmedicines-decision-making-2/ [cited 2020 Apr 20]

6. Kalil AC. Treating COVID-19-off-label drug use, compassionate use and randomized clinical trials during pandemics. JAMA 2020 Mar 24. [Epub ahead of print] https://doi.org/10.1001/jama.2020.4742

7. Fanouriakis A, Kostopoulou M, Alunno A, Aringer M, Bajema I, Boletis JN, et al. 2019 update of the EULAR recommendations for the management of systemic lupus erythematosus. Ann Rheum Dis 2019;78:736-45. https://doi.org/10.1136/annrheumdis-2019-215089
8. Canadian Hydroxychloroquine Study Group. A randomized study of the effect of withdrawing hydroxychloroquine sulfate in systemic lupus erythematosus. N Engl J Med 1991;324:150-4. https://doi.org/10.1056/NEJM199101173240303

9. Freeman C. Prescribing hydroxychloroquine for COVID-19 [open letter to prescribers]. Canberra: Pharmaceutical Society of Australia; 2020 Mar 21. https://www.psa.org.au/ prescribing-hydroxychloroquine-for-covid-19 [cited 2020 Apr 20]

10. Hendrie D. Many use malaria drug as coronavirus protection - but evidence lacking. News GP 2020 Mar 23. https://www1.racgp.org.au/newsgp/clinical/many-flock-tomalaria-drug-for-coronavirus-protect [cited 2020 Apr 20]

11. Medical Board of Australia. Good medical practice: a code of conduct for doctors in Australia. 2014 Mar 17. https://www.medicalboard.gov.au/Codes-GuidelinesPolicies/Code-of-conduct.aspx [cited 2020 Apr 21]

12. Bird S. The pitfalls of prescribing for family and friends. Aust Presc 2016;39:11-3. https://doi.org/10.18773/ austprescr.2016.002

13. Australian Government Department of Health. Australian Health Protection Principal Committee (AHPPC) coronavirus (COVID-19) statements on 7 April 2020. Advice on off-label medicines for treatment and prophylaxis of COVID-19. https://www.health.gov.au/news/australian-healthprotection-principal-committee-ahppc-coronaviruscovid-19-statements-on-7-april-2020\#advice-on-offlabelmedicines-for-treatment-and-prophylaxis-of-covid19 [cited 2020 Apr 20] 